\title{
STUDIES IN DISORDERS OF MUSCLE. VII. CLINICAL MANI- FESTATIONS AND INHERITANCE OF A TYPE OF PERIODIC PARALYSIS WITHOUT HYPOPOTASSEMIA ${ }^{1}$
}

\author{
By FRANK H. TYLER, F. E. STEPHENS, F. D. GUNN, ANd G. T. PERKOFF \\ (From the Laboratory for the Study of Hereditary and Metabolic Disorders, the Departments \\ of Medicine and Pathology, and the Division of Biology, University of Utah, \\ Salt Lake City, Utah)
}

(Submitted for publication December 13, 1950; accepted, March 12, 1951)

\section{INTRODUCTION AND REVIEW OF LITERATURE}

The report by several investigators in 1937 and 1938 that the paralytic attacks in the disease, periodic paralysis, were associated with depressed serum potassium values led to the conclusion that the disorder is the consequence of some fault in the regulation of serum potassium levels $(1-4)$. Ample support for such a concept appeared to be given by other observations. Thus, depletion of serum potassium in various other clinical circumstances, as in the recovery from diabetic acidosis and in the Addisonian patient overtreated with desoxycorticosterone acetate, is associated with flaccid paralysis. Again, it is known that hypopotassemia results in cardiac arrest in diastole and causes impaired contractility of muscle in vitro. Finally, the balance studies of Danowski and associates (5) showed that, in the patients they studied, the attacks of paralysis were preceded by the movement of potassium into the intracellular phase and that urinary potassium excretion as well as the serum potassium concentration decreased.

Talbot (6) in 1941 summarized the data concerning more than 400 cases of periodic paralysis. The disorder has been usually referred to as familial or family periodic paralysis. It seems best to us as it did to Talbot to call the disease periodic paralysis, specifying the hereditary nature of the disorder when it is genetically determined, and referring to the other cases as sporadic, associated with thyrotoxicosis or in other ways specifying the mechanism involved where it is known. Talbot concluded that the syndrome probably represented a clinical entity due to a single metabolic dysfunction.

In our study of a kindred in which 33 individuals

1 This study was supported in part by a grant from the United States Public Health Service. with clinically typical periodic paralysis were known to have occurred, we observed no striking hypopotassemia during attacks in the patients whom we studied in detail. This led us to undertake a critical review of the data dealing with this disorder in the literature. A poor correlation between the onset and the severity of the attacks and the magnitude of the depression of serum potassium values has been noted and commented upon by several authors, including Talbot (6). Occasional instances of paralysis without depression of serum potassium levels have been reported (7). Furthermore, the levels of serum potassium found during attacks in patients with periodic paralysis usually have not been as low as those observed in patients who do not carry this genetic trait but who have hypopotassemic paralysis resulting from better understood metabolic abnormalities $(3,6,8$, 9). A corollary observation is the apparent lack of specificity of potassium in relieving or preventing the paralysis in certain patients with periodic paralysis in contrast to its excellent effect in the other metabolic hypokaliemias $(1,6,10,11)$.

It seems probable, therefore, that periodic paralysis as described in the literature is produced by more than one mechanism or that the serum potassium depletion is not the fundamental disorder. Such anomalies as abnormal storage of glycogen as well as other changes in intracellular potassium metabolism might be responsible for these vagaries of the serum potassium levels. The lack of complete similarity of the hereditary cases suggests that different genetic mechanisms are involved, most probably multiple mutations. These mutations can be understood best by studying them in kindreds where the expression of the same gene in many individuals may be observed. This disorder, like many other human hereditary disorders 
such as hereditary muscular dystrophy, hereditary blindness, hereditary deafness, etc., must be broken down into specific genetic entities before it can be analyzed and interpreted adequately.

An examination of the genetic literature illustrates the diversity and variety of expression of periodic paralysis. The trait has been reported to be a dominant with skipped generations $(12,13)$, a complete dominant $(14,15)$, a recessive (6), and a sex-linked recessive (16). The gene has been reported as manifesting incomplete penetrance in females (6) and as having complete penetrance in both sexes (15). The expressivity may range from a slight recurrent weakness in one limb, as reported in one family (10), to paralysis so severe that nearly the entire body is paralyzed, in other families (13). Again, the paralysis may be so extreme in some cases as to cause death $(13,14)$.

The duration of an attack in the members of some families may range from a few minutes to several days while in other families an individual may never be affected for more than a few hours (6). In certain families the attacks are rare, occurring once or twice in a lifetime or two or three times in a year or in a decade (6). In contrast, a case has been reported in which the attacks occurred daily (17). The onset has ranged from four to 35 years in one family (15), was consistently at 18 or 19 years of age in another (14) and, in yet another, the condition was evident in infants less than a year old (18). The attacks have been reported to cease in one family after the fourth decade (15).

Periodic paralysis has been observed in association with other diseases. One family was reported to have migraine as well as periodic paralysis (13) and another family with the trait had migraine and muscular atrophy that developed after years of attacks of paralysis (19). Others report the association of periodic paralysis with exophthalmic goiter $(20-22)$. The transition of periodic paralysis to spinal muscular atrophy also has been described (23).

Many diverse clinical observations and even more diverse interpretations of these findings have been reported. Attacks have been thought to be precipitated by local application of cold (17), by glucose $(5,6,24,25)$, by water diuresis $(26)$, and by insulin $(2,24,25)$. In other cases, none of these was effective in bringing about an attack (10, $25,26)$. Potassium chloride, thyroid extract $(25)$, cholinergic drugs (26), and adrenal extract (2) have all been used effectively and ineffectively as therapeutic agents. Reports concerning potassium, sodium, phosphate, and magnesium ion levels have been conflicting $(1,2,5,7,10,22,27,28)$.

It has been postulated that the defect is related to the central nervous system, to the permeability of muscle cells, to hepatic or muscular glycogenesis or to a chronic deficit of potassium in the muscle $(10,28)$.

In addition to the analysis of the genetic pattern in this kindred we have made certain clinical and laboratory studies on some of these patients. We have studied methods of precipitating attacks, the effect of administering glucose or glucose and insulin, the effect of exercise and of enforced rest, and the correlation of these factors to serum potassium, sodium, magnesium, phosphate and blood glucose levels. Gross and microscopic examination of biopsy material from skeletal muscle as well as determination of its glycogen content also have been carried out.

\section{METHODS}

Pedigree, genetic and clinical data were secured by interviews with the members of the kindred. The trait in this kindred is of such a nature that it is readily identified by the members of the families, and their reports of its occurrence have been consistently accurate in those patients whom we have examined. Where it was necessary to obtain information regarding individuals who are now dead, a check was made from as many different sources as possible in order to be sure that the data were accurate. Blood types and ability to taste for phenylthiocarbamide (PTC) were determined for use in linkage studies.

Five patients were studied in detail on the metabolic ward of the laboratory. A full history, physical examination and clinical laboratory investigation, as well as certain special determinations as summarized in the introduction, were carried out. Blood glucose values were determined by the method of Nelson (29) on alkaline zincbarium filtrates of whole blood collected in a fluorideoxalate anticoagulant. Serum potassium and sodium were measured on a flame photometer (30). Serum magnesium values were estimated by the colorimetric method of Kunkel and coworkers (31), muscle glycogen by the method described by Good and colleagues (32). The remaining chemical and hematologic methods used have been described in detail in other papers of this series and will not be reviewed here $(33,34)$. 


\section{CLINICAL DESCRIPTION OF THE TRAIT}

The clinical manifestations of the trait as observed in this kindred consisted of episodes of weakness or flaccid paralysis. Such attacks began and ended insidiously. They lasted from a few minutes to many hours or even several days in rare instances. In severe attacks all of the skeletal muscles were involved except those of facial expression, mastication, deglutition, speech, and respiration (diaphragm). Respiratory embarrassment of a severe character was not observed in any of these patients. In milder episodes localized areas were sometimes involved, usually the large muscles of the legs, arms or back, although an occasional individual had attacks in which only local involvement of the hands occurred. The pattern was usually symmetrical on both sides of the body. The paralysis was flaccid, deep tendon reflexes were absent and electrical excitability of the muscle was greatly reduced or lost.

The attacks began most frequently in the early morning and not infrequently were present on awakening. Activity tended to decrease the degree of weakness present if paralysis did not preclude movement. On the other hand, strenuous exercise which was followed by complete inactivity very frequently initiated an episode. This was the most reliable manner of initiating attacks in the patients whom we studied. Paralysis did not occur while the patient continued to be active but the more strenuous the activity and the more complete the ensuing rest, the more probable it was that a severe attack would result. The patients consistently reported that they could "fight off" an incipient attack by persistent activity. This, it may be noted, is the exact converse of the effect of activity and rest in myasthenia gravis.

A number of other factors also appeared to play a role in the precipitation of attacks. A heavy meal or, less frequently, the ingestion of a large amount of carbohydrate, particularly if taken before bed time, sometimes preceded an attack on the ensuing morning or day. No patient reported attacks precipitated by high carbohydrate intake during the preceding two hours.

Some patients reported no difficulty from food ingestion regardless of amount. Still other periods of recurrent severe episodes occurred without any apparent relation to the activities of the pa- tient. These were just as severe as those having apparent relationship to preceding exercise or other factors which the patient regarded as responsible for the attack.

During the attacks there were no symptoms other than those which related to the weakness itself, except that during severe paralysis marked perspiration usually occurred. That this may precede the paralysis and possibly be a factor in its development was suggested by the drenching night sweats which frequently preceded morning attacks. One patient reported that profuse sweating preceded most of his severe attacks. On the other hand, the profuse perspiration induced by heavy work in hot weather does not induce paralysis unless it is followed by more or less complete inactivity.

The initial attacks occurred in the first year of life and the parents who were well acquainted with the disorder were able to recognize the presence of the trait regularly during the first months of life. The episodes tended to be most frequent during childhood and adolescence, gradually decreasing in severity and frequency with advancing age although they still occurred in aged individuals. There was a moderate degree of variability in the severity of the syndrome from patient to patient, some being only occasionally inconvenienced, others having attacks of such severity that they must miss work on the average of one day per week. In the individual patient as well, a long period during which little trouble was experienced might be followed by frequently recurrent attacks for periods lasting a few days or many months. Such periods were often associated with continued emotional stress.

On physical examination two observations could be made almost routinely even though the patient felt that he was normal at the time. A slight but definite degree of weakness was present in the extensors of the arms and legs which was sufficient to show up in sharp contrast to the good strength present in the flexors. These patients presented the appearance of muscular, hearty individuals, a fact which had caused certain of the male members no end of difficulty in dealing with the armed services where weakness in an apparently muscular individual is presumed to be evidence of laziness. The muscular appearance was particularly marked in the calf muscles and extensors of the arms, and 
was indistinguishable clinically from the pseudohypertrophy of childhood progressive muscular dystrophy, as previously discussed by one of us (35). Pathologically the findings are very different from those observed in the pseudohypertrophy of dystrophy, as will be described below.

The syndrome appears in both sexes. The symptoms are usually more severe in the males, possibly because of the somewhat more vigorous activity in which they engage and the relationship of exercise to the episodes of paralysis outlined above.

\section{LABORATORY STUDIES}

No significant laboratory abnormality has been observed in the five male patients whom we have studied in detail except for the occurrence of high serum uric acid levels in two. No history suggestive of gouty arthritis was obtained on these nor on other normal or abnormal members of the group. Table I is a summary of the routine and certain special determinations which were performed. The fasting serum potassium values, taken at times when no significant degree of paralysis existed, were normal. Those presented are representative figures taken from a large series of determinations, none of which was abnormal. The normal creatinine excretion values are consistent with the apparently normal muscle mass. Creatine excretion was insignificant. Volumes of packed red cells ranging about 50 per cent correspond to normal male values for this area which is over 4,000 feet above sea level.
The results of some of our attempts to induce attacks by the administration of glucose or glucose and insulin are summarized in Table II. None of these was successful in producing a significant change in the degree of disability present at the start of the tests although serum potassium levels of about 3.1 meq./L were observed on several occasions.

Simultaneous urine collections showed a marked drop in the excretion of potassium, as is regularly observed during the hypopotassemia following carbohydrate or insulin administration. Thus the metabolic picture observed by Danowski has been reproduced without precipitating an attack of paralysis. The time relationships are shorter which possibly is a significant factor in the problem. No exactly similar experiments have been carried out in other cases of periodic paralysis as far as the authors are aware and we have not had an opportunity up to the present to duplicate the observation in a patient showing definite hypopotassemia during spontaneous attacks. It is noteworthy, however, that in nearly all of the previously reported patients in whom carbohydrate or insulin appeared to have been related to attacks, the paralysis developed after a delay of six or more hours and not at the time of maximum hypopotassemia. We observed no significant increase in attacks of paralysis in our patients during the 24 hours following these experiments.

Glucose tolerance was certainly not impaired in any of these tests. The rather low 30 and 60 min-

TABLE I

Serum, whole blood and urine studies in hereditary periodic paralysis

\begin{tabular}{|c|c|c|c|c|c|}
\hline & $\begin{array}{c}\text { G. D. K. } \\
10 \\
\text { Male }\end{array}$ & $\begin{array}{c}\text { Bu. R. } \\
19 \\
\text { Male }\end{array}$ & $\begin{array}{c}\text { B1. R. } \\
22 \\
\text { Male }\end{array}$ & $\begin{array}{c}\text { T. K. B. } \\
23 \\
\text { Male }\end{array}$ & $\begin{array}{c}\text { M. M. } \\
27 \\
\text { Male }\end{array}$ \\
\hline $\begin{array}{l}\text { Potassium, meq./L } \\
\text { Sodium, meq./L } \\
\text { Magnesium, meq./L } \\
\text { Calcium, meq./L } \\
\text { Phosphate, mg./100 ml. as } \mathrm{P} \\
\text { CO }{ }_{2} \text { combining power, mM./L } \\
\text { Chloride, meq./L } \\
\text { Uric acid, mg./100 ml. } \\
\text { Total protein, gms./100 ml. } \\
\text { Albumin, gms./100 ml. } \\
\text { Fasting blood sugar, mg./100 ml. } \\
\text { Blood urea nitrogen, mg./100 ml. } \\
\text { Routine clinical urine examination } \\
\text { Creatinine, mg./24 hrs. urine } \\
\text { Creatine, mg./24 hrs. urine as creatinine } \\
\text { Hct., \% RBC } \\
\text { WBC in thousands } / \mathrm{mm}^{3}\end{array}$ & $\begin{array}{c} \\
\\
\\
104 \\
\\
\\
78 \\
10 \\
\text { Normal } \\
754 \\
70 \\
42 \\
9.0\end{array}$ & $\begin{array}{c}4.2 \\
144 \\
\\
25.9 \\
107 \\
7.8 \\
8.9 \\
6.6 \\
70 \\
12 \\
\text { Normal } \\
1,525 \\
200 \\
52 \\
6.8\end{array}$ & $\begin{array}{c}4.0 \\
141 \\
2.0 \\
4.5 \\
\\
5.5 \\
7.5 \\
5.2 \\
72 \\
15 \\
\text { Normal } \\
1,366 \\
0 \\
54 \\
8.6\end{array}$ & $\begin{array}{c}4.2 \\
138 \\
5.3 \\
3.3 \\
26.3 \\
7.9 \\
\\
72 \\
14 \\
\text { Normal } \\
\\
49 \\
8.3\end{array}$ & $\begin{array}{c}4.0 \\
144 \\
2.1 \\
5.5 \\
3.1 \\
26.1 \\
103 \\
4.8 \\
7.9 \\
5.9 \\
64 \\
12 \\
\text { Normal } \\
1,459 \\
73 \\
47 \\
7.4\end{array}$ \\
\hline
\end{tabular}


TABLE II

Blood sugar, serum potassium and serum phosphate values after oral or I.V. administration of glucose with or without insulin

\begin{tabular}{|c|c|c|c|c|c|c|c|c|c|}
\hline Patient and procedure & Time in minutes. & 0 & 30 & 60 & 90 & 120 & 150 & 180 & 240 \\
\hline $\begin{array}{l}\text { T. K. B. } \\
96 \text { gms. glucose } \\
\text { I.V. }\end{array}$ & $\begin{array}{l}\text { Blood glucose, mg./100 ml. } \\
\text { Serum potassium, meq./L } \\
\text { Serum sodium, meq./L } \\
\text { Serum phosphate, mg./100 } \\
\text { ml. as P }\end{array}$ & $\begin{array}{c}74 \\
4.2 \\
140 \\
3.7\end{array}$ & $\begin{array}{l}234 \\
\quad 4.1 \\
134 \\
\\
2.8\end{array}$ & $\begin{array}{r}48 \\
4.1 \\
137 \\
\\
3.0\end{array}$ & $\begin{array}{c}39 \\
4.1 \\
138 \\
3.1\end{array}$ & & $\begin{array}{r}62 \\
3.9 \\
137 \\
3.8\end{array}$ & & \\
\hline $\begin{array}{l}\text { T. K. B. } \\
100 \text { gms. glucose } \\
\text { orally }\end{array}$ & $\begin{array}{l}\text { Blood glucose, mg./100 ml. } \\
\text { Serum potassium, meq./L } \\
\text { Serum phosphate, mg./100 } \\
\text { ml. as P }\end{array}$ & $\begin{array}{r}72 \\
4.7 \\
4.2\end{array}$ & $\begin{array}{l}79 \\
3.6 \\
3.5\end{array}$ & $\begin{array}{l}88 \\
3.6\end{array}$ & $\begin{array}{c}72 \\
3.7 \\
3.6\end{array}$ & $\begin{array}{c}85 \\
3.7 \\
3.7\end{array}$ & & $\begin{array}{r}68 \\
4.2 \\
3.9\end{array}$ & $\begin{array}{r}82 \\
4.0 \\
3.9\end{array}$ \\
\hline $\begin{array}{c}\text { M. M. B. } \\
100 \text { gms. glucose } \\
\text { I.V. }\end{array}$ & $\begin{array}{l}\text { Blood glucose, mg./100 ml. } \\
\text { Serum potassium, meq./L } \\
\text { Serum phosphate, mg./100 } \\
\text { ml. as P }\end{array}$ & $\begin{array}{r}53 \\
4.8 \\
3.4\end{array}$ & $\begin{array}{r}207 \\
4.0 \\
3.1\end{array}$ & $\begin{array}{r}164 \\
3.5 \\
3.1\end{array}$ & \begin{tabular}{c|}
76 \\
3.5 \\
3.4
\end{tabular} & $\frac{34}{-}$ & & $\begin{array}{c}57 \\
3.5 \\
4.3\end{array}$ & $\begin{array}{r}62 \\
3.7 \\
4.4\end{array}$ \\
\hline $\begin{array}{l}\text { M. M. B. } \\
200 \text { gms. glucose } \\
\text { orally }\end{array}$ & $\begin{array}{l}\text { Blood glucose, mg. } \% \\
\text { Serum potassium, meq./L } \\
\text { Serum sodium, meq./L } \\
\text { Serum phosphate, mg./100 } \\
\text { ml. }\end{array}$ & $\begin{array}{c}64 \\
4.0 \\
144 \\
3.6\end{array}$ & $\begin{array}{l}107 \\
4.1 \\
143 \\
\\
3.2\end{array}$ & $\begin{array}{c}76 \\
4.5 \\
142 \\
\\
3.1\end{array}$ & $\begin{array}{c}67 \\
4.4 \\
142 \\
3.2\end{array}$ & $\begin{array}{c}82 \\
4.1 \\
142 \\
3.3\end{array}$ & & $\begin{array}{r}72 \\
3.7 \\
141 \\
3.5\end{array}$ & $\begin{array}{r}77 \\
4.4 \\
139 \\
\\
3.6\end{array}$ \\
\hline $\begin{array}{l}\text { Bl. R. } \\
35 \text { gms. glucose } \\
\text { I.V. }\end{array}$ & $\begin{array}{l}\text { Blood glucose, mg. } / 100 \mathrm{ml} \text {. } \\
\text { Serum potassium, meq./L } \\
\text { Serum phosphate, mg./100 } \\
\text { ml. as P }\end{array}$ & $\begin{array}{r}72 \\
3.8 \\
3.6\end{array}$ & $\begin{array}{r}170 \\
\cdot 3.4 \\
3.4\end{array}$ & $\begin{array}{r}52 \\
3.7 \\
3.6\end{array}$ & $\begin{array}{r}54 \\
3.9 \\
3.5\end{array}$ & & & \begin{tabular}{c|}
74 \\
4.3 \\
4.1
\end{tabular} & \\
\hline $\begin{array}{l}\text { Bl. R. } \\
100 \text { gms. glucose and } \\
25 \text { units insulin I.V. }\end{array}$ & $\begin{array}{l}\text { Blood glucose, mg./100 ml. } \\
\text { Serum potassium, meq./L } \\
\text { Serum magnesium, meq./L } \\
\text { Serum phosphate, mg./100 } \\
\text { ml. as P }\end{array}$ & $\begin{array}{r}106 \\
3.9 \\
2.0 \\
\\
4.6\end{array}$ & $\begin{array}{r}141 \\
3.6 \\
1.9 \\
\\
3.9\end{array}$ & $\begin{array}{c}86 \\
3.1 \\
1.6 \\
3.6\end{array}$ & $\begin{array}{c}80 \\
3.4 \\
1.9 \\
3.8\end{array}$ & & $\begin{array}{c}64 \\
3.7 \\
1.9 \\
4.3\end{array}$ & & \\
\hline $\begin{array}{l}\text { Bu. R. } \\
200 \text { gms. glucose and } \\
30 \text { units insulin I.V. }\end{array}$ & $\begin{array}{l}\text { Blood glucose, mg. } / 100 \mathrm{ml} \text {. } \\
\text { Serum potassium, meq. } / \mathrm{L} \\
\text { Serum phosphate, mg. } / 100 \\
\text { ml. as P }\end{array}$ & $\begin{array}{c}70 \\
3.7 \\
5.0\end{array}$ & $\begin{array}{r}187 \\
3.1\end{array}$ & $\begin{array}{c}14 \\
3.1\end{array}$ & $\begin{array}{c}25 \\
3.1\end{array}$ & $\begin{array}{c}39 \\
3.4\end{array}$ & $\begin{array}{l}53 \\
3.6\end{array}$ & \begin{tabular}{r|}
57 \\
4.2 \\
4.7
\end{tabular} & \\
\hline
\end{tabular}

ute blood glucose levels after oral administration might suggest either impaired absorption or increased glucose tolerance. Intravenous glucose tolerance tests using one-half gram of glucose per kilogram of body weight showed normal curves in three patients and no other evidence of altered carbohydrate metabolism could be obtained. During episodes of mild and severe paralysis we have obtained repeated serum samples which have been analyzed for sodium, potassium, and magnesium, as well as a number of other substances. All of these values have been consistently normal. A few are presented in Table III; the values during attacks are those obtained at the time paralysis was most severe.

Additional comment about the serum potassium values seems in order because of the many previous observations of depressed levels. On two occasions we have obtained multiple samples at approxi- mately 15 minute intervals during artificially induced attacks (exercise followed by enforced rest). The serum potassium values on these occasions varied over a narrow range ( 0.4 meq.) and showed no consistent pattern or correlation to the degree of paralysis at the time the serum was obtained. Electrocardiograms taken during the attacks showed no change from the control tracings.

We have observed no values below 3.5 meq./L except in association with the glucose-insulin infusions. All of the values were in the same range as observed in normal individuals in our laboratory.

Oral therapy with potassium chloride, either prophylactically or during an attack, failed to influence the course of the disorder. However, we have not had the opportunity to observe the effect of potassium given orally or intravenously during an episode of severe paralysis of more than about one hour's duration, and the possibility, albeit im- 
TABLE III

Serum electrolyte values before and at the time of maximum paralysis in four patients

\begin{tabular}{l|c|c|c|c|c}
\hline \hline & \multicolumn{3}{|c|}{$\begin{array}{c}\text { Serum potassium } \\
\text { meq./L. }\end{array}$} & \multicolumn{2}{c}{$\begin{array}{c}\text { Serum magnesium } \\
\text { meq. } / L .\end{array}$} \\
\cline { 2 - 5 } Patient & $\begin{array}{c}\text { Before } \\
\text { attack }\end{array}$ & $\begin{array}{c}\text { During } \\
\text { attack }\end{array}$ & Change & Control & $\begin{array}{c}\text { During } \\
\text { attack }\end{array}$ \\
\hline G. D. K. & 5.7 & 5.7 & 0.0 & & \\
Bu. R. & 4.2 & 5.0 & +0.8 & & \\
Bl. R. & 3.9 & 3.7 & -0.2 & 2.0 & 2.0 \\
& 4.2 & 4.2 & 0.0 & & 1.95 \\
& 5.4 & 5.4 & 0.0 & & 2.2 \\
& 3.6 & 4.0 & +0.4 & & \\
T. K. B. & 3.8 & 4.2 & +0.4 & & \\
\hline
\end{tabular}

probable, exists that the effect might be different under such circumstances. Actually all of the group who have taken potassium prophylactically by mouth dislike the medication and report that they have experienced just as many and as severe attacks while receiving such therapy as at other times. In addition, a number have experienced nausea, dizziness, and a vague lack of well-being while taking potassium, and all have discontinued it within a few weeks of its first administration.

\section{PATHOLOGY}

Three patients submitted to biopsy of their enlarged gastrocnemius muscle mass. Grossly the muscles appeared essentially normal; contracted on mechanical stimulation, and showed no evidence of fatty replacement or of fibrosis.

Microscopically, characteristic degenerative changes were recognized in the muscle of all three patients but the degree of change varied widely. In the sample which showed the slightest degree of alteration, most of the fibers were well preserved and their strial markings were clearly defined but their diameters exhibited greater than normal variation. Some fibers were unusually slender and were stained more strongly with eosin than were the fibers of normal size. Irregular clusters of nuclei appeared along the more slender portions and, in a few foci, appeared to replace the substance of fibers. In other places, portions of fibers were missing and the spaces were partly filled by pycnotic nuclei, monocytes, polymorphonuclear neutrophils, fibrocytes and a few well preserved muscle nuclei. The most characteristic feature was the presence of vacuoles near the centers of a few fibers and appearing at sites of fusiform enlargement (Figure 1). The largest of these were round, fusiform or oval, occupied the entire diameter of the fiber and were limited laterally only by sarcolemma. The smaller spaces appeared to arise within sites of basophilic degeneration where longitudinal and transverse striae were absent and acidophilic granules appeared. The vacuoles occurred as multiple foci of rarefaction, sometimes lined up along the axis of the fiber like a string of beads. The larger vacuoles, apparently formed by coalescence of several small ones, often contained acidophilic granules and occasionally were filled with faintly basophilic coarse granules. A few contained one or two pycnotic nuclei.

In the sample of muscle exhibiting the most advanced degree of degeneration, very few muscle fibers appeared normal although many retained their striae. Irregularly swollen, hyalinized fibers alternated with degenerated fibers containing vacuoles of all sizes and shapes. Areas of segmental disintegration were often associated with an increased number and pycnosis of nuclei. Some portions of fibers were represented by amorphous acidophilic debris.

Frozen sections stained with Sudan IV and hematoxylin failed to show abnormal quantities or distribution of lipids.

Sections of muscle, fixed in absolute alcohol and stained by Best's carmine method, showed marked irregularity of distribution of glycogen granules. Many coarse granules were found in those portions of the fibers which appeared swollen and degenerated. Some of the vacuoles contained amorphous masses and coarse granules which were carmine-positive but many of the vacuoles were entirely empty or contained unstained debris.

Two of the biopsy specimens were analyzed for total glycogen content. The values, together with those of two control specimens from human material, are listed in Table IV. It will be noted that all of the values fall within the normal range for muscle glycogen.

TABLE IV Glycogen content of muscle
Patient

M. M. B.

Bu. R.

Control 1 Control 2
Glycogen as gms. tissue

1.01

0.46

1.33

0.76 


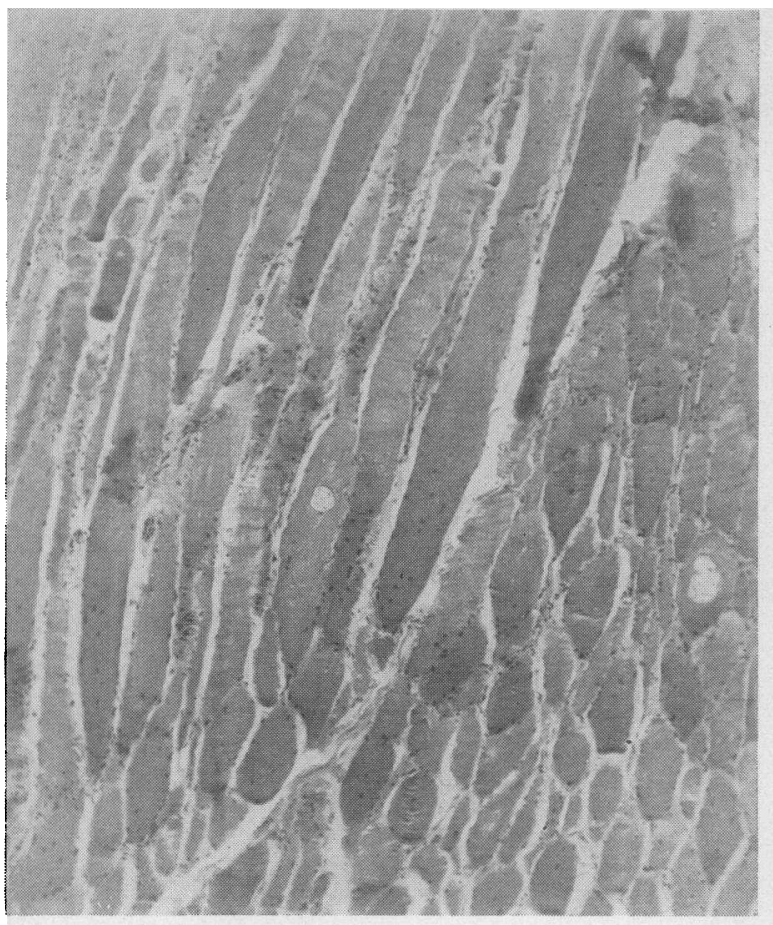

Fig. 1a.

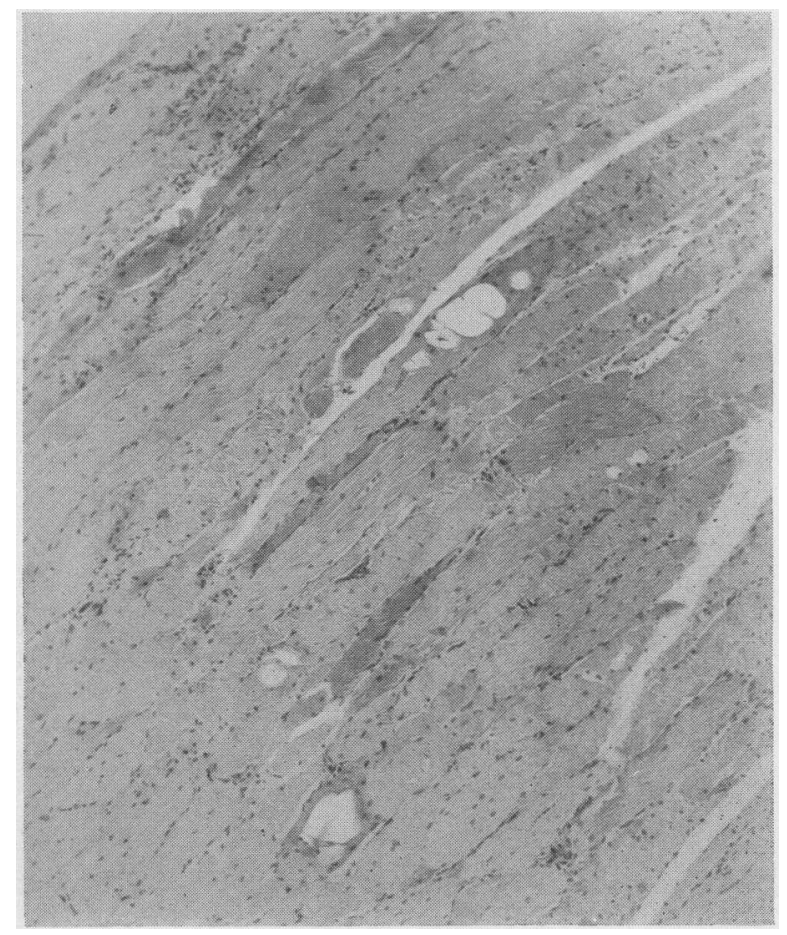

FIG. 1b.

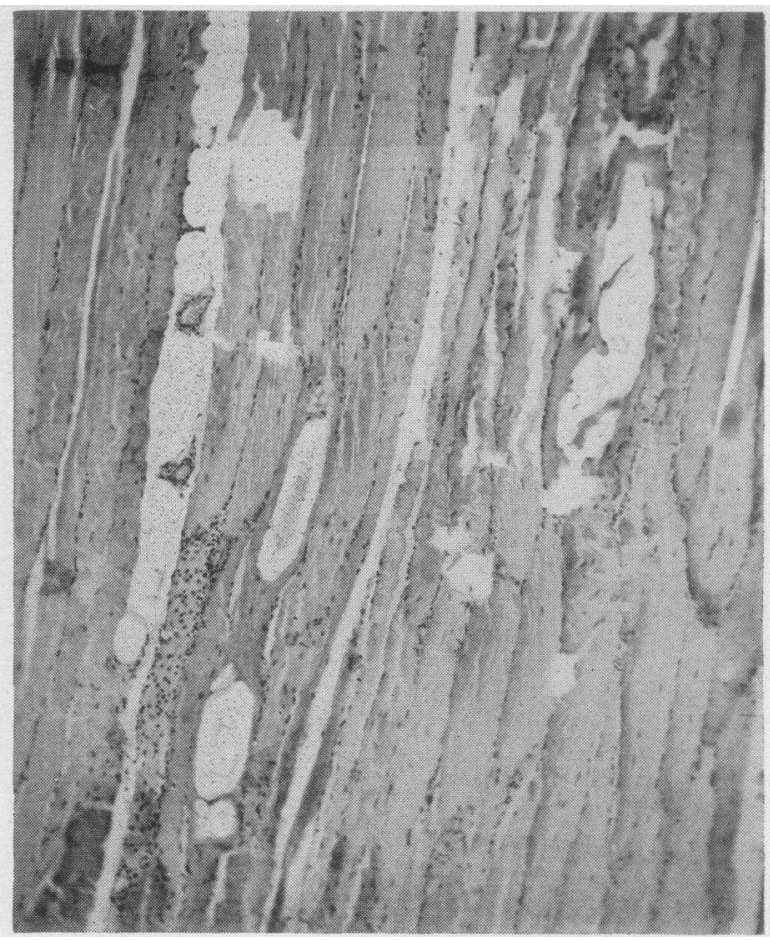

FIG. 1c.

Fig. 1. Three Photomicrographs Illustrating the Microscopic Changes Found in Biopsy Specimens from the Gastrocnemius Muscle

Note the central location of the vacuoles in (a) both in longitudinal and cross sections and the irregular size of the muscle fibers. The more extensive changes in (b) and (c) are apparent, some fibers showing almost complete replacement. The sections were stained with hematoxylin and eosin and are magnified about 78 diameters.

\section{FAMILY HISTORY}

Figure 2 is a pedigree chart of the kindred reported in this study. I-1 and I-2 migrated to Utah in 1854. They had three daughters (II-1, 2, 3). II- 1 died at the age of 13 . III-8 and 9, daughters of II-3, state that their mother was affected with periodic paralysis and that she told them that her mother (I-1) and sister (II-2) were also affected. II-2 had five children all of whom are now dead. Interviews with their children, or with other members of the family who were in a position to know of their condition, indicated that none of the five children nor their descendants was affected with periodic paralysis. The condition of II-1 is not known. 


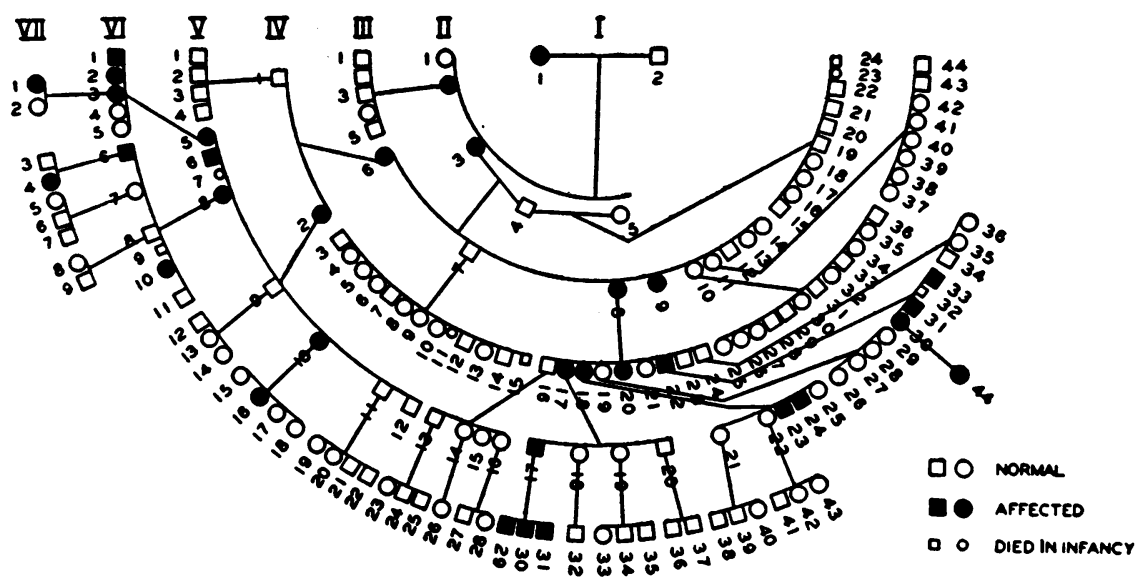

Fig. 2. Pedigree Chart of Kindred

Note that only affected individuals transmit the trait.

The husband of II-3 was a polygamist. He had ten children by his second wife (II-5) none of whom was affected with periodic paralysis. With the exception of I-1 and II-2, all of the known cases of periodic paralysis in this kindred descended from II-3. Nearly all members of the kindred are now living in Utah.

\section{INHERITANCE}

Examination of Figure 2 shows that the trait is transmitted through one family line and that it

TABLE $v$

Segregation of children of 16 individuals affected with periodic paralysis

\begin{tabular}{|c|c|c|c|c|c|c|}
\hline \multicolumn{2}{|c|}{ Family } & \multicolumn{2}{|c|}{ Affected } & \multicolumn{2}{|c|}{ Normal } & \multirow{2}{*}{$\begin{array}{l}\text { Condi- } \\
\text { tion un- } \\
\text { known }\end{array}$} \\
\hline $\begin{array}{c}\text { Genera- } \\
\text { tion }\end{array}$ & Number & Male & Female & Male & Female & \\
\hline $\begin{array}{c}\text { I } \\
\text { II } \\
\text { II } \\
\text { III } \\
\text { III } \\
\text { IV } \\
\text { IV } \\
\text { IV } \\
\text { IV } \\
\text { V } \\
\text { V } \\
\text { V } \\
\text { V } \\
\text { V } \\
\text { VI } \\
\text { VI }\end{array}$ & $\begin{array}{r}1 \\
2 \\
3 \\
6 \\
8 \\
2 \\
17 \\
18 \\
22 \\
5 \\
8 \\
10 \\
17 \\
30 \\
\cdot 3 \\
6\end{array}$ & $\begin{array}{l}\text { 二 } \\
\text { 二 } \\
1 \\
1 \\
1 \\
2 \\
2 \\
1 \\
1 \\
-3 \\
- \\
-\end{array}$ & $\begin{array}{c}2 \\
3 \\
1 \\
3 \\
3 \\
- \\
1 \\
2 \\
1 \\
1 \\
1 \\
1 \\
1\end{array}$ & $\begin{array}{l}\overline{4} \\
2 \\
1 \\
3 \\
3 \\
1 \\
\overline{-} \\
\overline{2} \\
\overline{2} \\
\overline{-} \\
\overline{1}\end{array}$ & $\begin{array}{r}-1 \\
4 \\
2 \\
2 \\
3 \\
2 \\
1 \\
- \\
-1 \\
-\end{array}$ & 1 \\
\hline Totals & & 12 & 20 & 17 & 19 & 1 \\
\hline
\end{tabular}

never occurs in a child unless it has also occurred in a parent. Table $\mathrm{V}$ shows the numbers of normal and affected individuals by sex in the families in which the trait occurred. It includes all of the known offspring of individuals who have periodic paralysis in this kindred. Table VI compares the totals of Table $\mathrm{V}$ to the expected results if the trait is inherited as a dominant with complete penetrance.

It is apparent that the trait occurs in approximately the same frequency in males and females and that approximately one-half of the children of an affected parent show the trait. This suggests that in this kindred, periodic paralysis is attributable to a simple dominant gene having complete penetrance. The deviation from the expected incidence is very slight. Since no two individuals showing the trait and no two relatives have married, affected individuals must be presumed to be heterozygous $(\mathrm{Pp})$. The crosses, therefore, which have produced affected children, are back crosses $(\mathrm{Pp} \times \mathrm{pp})$ and should produce one-half affected and one-half normal children. Since we have no homozygous individuals, there is no way of deter-

TABLE VI

Statistical comparison of data on this kindred with the theoretic behavior of a dominant trait

\begin{tabular}{c|c|c|c|c|c}
\hline & Observed & $\begin{array}{c}\text { Calcu- } \\
\text { lated }\end{array}$ & $\begin{array}{c}\text { Devia- } \\
\text { tion }\end{array}$ & S.E. & D./S.E. \\
\hline $\begin{array}{c}\text { Affected } \\
\text { Normal }\end{array}$ & 32 & 34 & 2 & 4.123 & .485 \\
\hline
\end{tabular}


mining whether or not the dominance is complete. It is possible that the trait would be expressed differently in the homozygous condition.

Blood samples have been taken and determinations made for $A, B, M, N$ and the various $R h$ antigens. Taste reactions to PTC were also determined. It was possible to obtain data from nearly all of the families segregating for paralysis who are now living. The data, however, were insufficient to warrant any conclusion regarding linkage relationships.

\section{EUGENIC IMPLICATIONS}

In this kindred, periodic paralysis can be detected readily by members of the families concerned. Each individual showing the trait is heterozygous and stands an equal chance of transmitting or not transmitting it to each of his children. The trait can be eliminated only if each affected individual refrains from having children. Unaffected individuals do not transmit the trait.

\section{DISCUSSION}

A number of unanswered problems remain concerning the disorder which we have observed in this group of people. Clinically the process is nearly identical with previously described cases of periodic paralysis whether hereditary or apparently sporadic. On the other hand, the failure to demonstrate any relationship of the attacks of paralysis to serum electrolyte concentrations, particularly the absence of hypopotassemia, sets the group apart from the best studied cases reported in the literature. Were it not for the defects which were discussed earlier, in the concept that serum potassium depletion is the fundamental mechanism leading to the paralysis in other cases, it might be concluded that we have been dealing with an entirely different disorder. This is hardly justified, however, in the light of the variability of the previously reported cases and the clinical indistinguishability of this syndrome from them. It is possible that all types of periodic paralysis are due to a single pathogenetic mechanism the nature of which has not been identified. However, the evident hypopotassemia seen in other patients makes this rather improbable, and therefore it is more likely that there are two or more types of periodic paralysis.
The frequently reported relationship of attacks to carbohydrate ingestion led us to postulate the possibility of some abnormality in the immediate availability of glycogen in muscle for the production of energy. Our studies to date have yielded no evidence to confirm such a theory; instead they have only served to emphasize the poor relationship between carbohydrate administration and attacks in this kindred.

The unusual pathologic picture of vacuolization of muscle fibers has been observed before, as far as we are aware, only in acute traumatic or infectious injury of muscle or in experimental obstruction of the deep lymphatics. The lack of inflammatory cells or evidence either clinically or pathologically of lymph stasis in these patients is not consistent with such an explanation here, however. A somewhat similar but more severe lesion has been observed in glycogen storage (von Gierke's) disease in children. The possibility that the disorder which we have described represents a related phenomenon in which only the muscle was involved seemed reasonable. However, our inability to demonstrate excess total glycogen or microscopic distribution of glycogen in the muscle fiber characteristic of that disorder makes this highly improbable.

The clean-cut genetic pattern of dominant inheritance with complete penetrance which we have found is in contrast to the findings in some of the previously reported families. This would appear to be additional evidence of the multiple character of the genetic mechanisms which result in the clinical syndrome of periodic paralysis. However, as we have emphasized previously (36), it is difficult to obtain reliable genetic data unless many of the normal and abnormal individuals are examined. In many published reports this was not done.

\section{CONCLUSIONS}

1. A study of periodic paralysis occurring in 33 individuals in seven generations of a single kindred is reported.

2. Clinically the disorder begins in infancy with recurrent attacks of weakness or flaccid paralysis. Some extensor weakness and enlargement of muscles is evident at all times.

3. The attacks are most consistently produced by vigorous exercise followed by complete rest. 
4. No correlation of the attacks with the serum potassium or other electrolyte concentrations could be established.

5. An unusual pathologic picture of vacuolization of scattered muscle fibers was found in biopsy material. Neither fat nor glycogen could be demonstrated in the vacuoles and it is presumed that they contained only edema fluid.

6. The pattern of inheritance is that characteristic of a simple mendelian dominant trait with complete penetrance.

\section{ACKNOWLEDGMENTS}

We are deeply indebted to Dr. Virginia Davenport and Dr. Harold Brown for certain of the electrolyte determinations.

\section{REFERENCES}

1. Aitken, R. S., Allott, E. N., Castleden, L. I. M., and Walker, M., Observations on a case of familial periodic paralysis. Clin. Sc., 1937, 3, 47.

2. Gammon, G. D., Austin, J. H., Blithe, M. D., and Reid, C. G., The relation of potassium to periodic family paralysis. Am. J. Med. Sc., 1939, 197, 326.

3. Ferrebee, J. W., Atchley, D. W., and Loeb, R. F., A study of electrolyte physiology in a case of familial periodic paralysis. J. Clin. Invest., 1938, 17, 504.

4. Pudenz, R. H., McIntosh, J. F., and McEachern, D., The role of potassium in familial periodic paralysis. J. A. M. A., 1938, 111, 2253.

5. Danowski, T. S., Elkinton, J. R., Burrows, B. A., and Winkler, A. W., Exchanges of sodium and potassium in familial periodic paralysis. J. Clin. Invest., 1948, 27, 65.

6. Talbot, J. H., Periodic paralysis : a clinical syndrome. Medicine, 1941, 20, 85.

7. Watson, C. W., Familial periodic paralysis. Report of a case showing no changes in serum potassium level with a description of electroencephalographic findings. Yale J. Biol. \& Med., 1946, 19, 127.

8. Castleden, L. I. M., The effect of adrenalin on the serum potassium level in man. Clin. Sc., 1938, 3, 241.

9. Allott, E. N., and McArdle, B., Further observations on familial periodic paralysis. Clin. Sc., 1938, 3, 229.

10. Ziegler, D. K., Familial periodic paralysis. Report on two families, with observations on the pathogenesis of the syndrome. Arch. Int. Med., 1949, 84, 419.

11. Frankel, M., Groen, J., and Willebrands, A. F., Low serum potassium level during recovery from diabetic coma. Arch. Int. Med., 1948, 80, 728.

12. Schmidt, A. K. E., Die paroxysmale Lähmung. Julius Springer, Berlin, 1919.
13. Holtzapple, G. E., Periodic paralysis. J. A. M. A., 1905, 45, 1224.

14. MacLachlan, T. K., Familial periodic paralysis. Description of six cases occurring in three generations of one family. Brain, 1932, 55, 47.

15. Oliver, C. P., Ziegler, M., and McQuarrie, I., Hereditary periodic paralysis in a family showing varied manifestations. Am. J. Dis. Child., 1944, 68, 308.

16. Khan, M. Y., Familial periodic paralysis. Indian M. Gaz., 1935, 70, 28.

17. Zabriskie, E. G., and Frantz, A. M., Familial periodic paralysis. Bull. Neurol. Inst., 1932, 2, 57.

18. Buzzard, E. F., Three cases of family periodic paralysis, with a consideration of the pathology of the disease. Lancet, 1901, 2, 1564.

19. von Storch, T. J. C., On the treatment of migraine. M. Clin. North America, 1941, 25, 1317.

20. Dunlap, H. F., and Kepler, E. J., A syndrome resembling familial periodic paralysis occurring in the course of exophthalmic goiter. Endocrinology, 1931, 15, 541.

21. Morrison, S., and Levy, M., The thyroid factor in family periodic paralysis. Arch. Neurol. \& Psychiat., 1932, 28, 386.

22. Hildebrand, A. G., and Kepler, E. J., Familial periodic paralysis associated with exophthalmic goitre. J. Nerv. \& Ment. Dis., 1941, 94, 713.

23. Biemond, A., and Daniels, A. P., Familial periodic paralysis and its transition into spinal muscular atrophy. Brain, 1934, 57, 91.

24. Holmes, J. M., Familial periodic paralysis. Brit. M. J., 1941, 1, 80.

25. Wolf, A., The effective use of thyroid in periodic paralysis. New York State J. Med., 1943, 43, 1951.

26. Favill, J., and Rennick, C. F., A case of family periodic paralysis. Arch. Neurol. \& Psychiat., 1924, 11,674 .

27. Milhorat, A. T., and Toscani, V., Studies in diseases of muscle. VII. Metabolism of calcium, phosphorus and magnesium in progressive muscular dystrophy, myotonia atrophica and familial periodic paralysis. Arch. Neurol. \& Psychiat., 1939, $41,1130$.

28. Stewart, H. J., Smith, J. J., and Milhorat, A. T., Electrocardiographic and serum potassium changes in familial periodic paralysis. Am. J. Med. Sc., 1940, $199,789$.

29. Nelson, N., Photometric adaptation of Somogyi method for determination of glucose. J. Biol. Chem., 1944, 153, 375.

30. Hald, P. M., The flame photometer for measurement of sodium and potassium in biological material. J. Biol. Chem., 1947, 167, 499.

31. Kunkel, H. O., Pearson, P. B., and Schweigert, B. S., Photoelectric determination of magnesium in body fluids. J. Lab. \& Clin. Med., 1947, 32, 1027.

32. Good, C. H., Kramer, H., and Somogyi, M., The determination of glycogen. J. Biol. Chem., 1933, $100,485$. 
33. Tyler, F. H., and Perkoff, G. T., Studies in disorders of muscle. VI. Is progressive muscular dystrophy a metabolic or endocrine disorder? Arch. Int. Med., in press.

34. Tyler, F. H., Studies in disorders of muscle. VIII. Renal function and the excretion of creatine and creatinine in progressive muscular dystrophy. To be published.
35. Tyler, F. H., Studies in disorders of muscle. III. "Pseudohypertrophy" of muscle in progressive muscular dystrophy and other neuromuscular diseases. Arch. Neurol. \& Psychiat., 1950, 63, 425.

36. Tyler, F. H., and Stephens, F. E., Studies in disorders of muscle. II. Clinical manifestations and inheritance of facioscapulohumeral dystrophy in a large family. Ann. Int. Med., 1950, 32, 640. 